EDUR • Educação em Revista. 2021; 37:e25804 DOI: http://dx.doi.org/10.1590/0102-469825804

() (1) https://creativecommons.org/licenses/by/4.0/

ARTIGO

\title{
GÊNERO E GERAÇÃO: DIMENSÕES DO CUIDADO NAS RELAÇÕES EDUCATIVAS NA EDUCAÇÃO INFANTIL
}

\author{
JULIANA SCHUMACKER LESSA ${ }^{1}$ \\ ORCID: https://orcid.org/0000-0003-3884-8309 \\ MÁRCIA BUSS-SIMÃO \\ ORCID: https://orcid.org/0000-0001-6076-0640
}

\begin{abstract}
RESUMO: O artigo resulta de duas pesquisas etnográficas com crianças, realizadas em contextos públicos de Educação Infantil e tem por objetivo analisar as relações entre as dimensões do cuidado, gênero e geração, a partir do quadro teórico correspondente às principais referências utilizadas nas pesquisas, fundamentadas em perspectivas dos Estudos Sociais da Infância, no diálogo com a Teoria Social. O confronto entre teoria e empiria permitiu a emergência de categorias e eixos temáticos que configuraram os resultados das suas análises, circunscritas nas relações educativas com crianças. A análise resultante do diálogo entre as duas pesquisas (BUSS-SIMÃO, 2012; LESSA 2019) anuncia as categorias relações geracionais (LESSA, 2019); processos de geracionalização; ordem geracional (ALANEN, 1994; 2012); fronteiras de gênero; neutralização (THORNE, 1993), e; relações inter e intragênero (KELLE 1997, 1999, 2000) como importantes contributos para a análise crítica da prática educativo-pedagógica na Educação Infantil.
\end{abstract}

Palavras-chave: Educação Infantil, processos geracionais, relações de gênero, cuidado, crianças.

\section{GENDER AND GENERATION: DIMENSIONS OF CARE IN EDUCATIONAL RELATIONSHIPS IN EARLY CHILDHOOD EDUCATION}

\begin{abstract}
The article results from two ethnographic researches with children, carried out in public contexts of Early Childhood Education and aims to analyze the relations between the dimensions of care, gender and generation, from the theoretical framework corresponding to the main references used in the researches, based on perspectives of the Social Studies of Childhood, in dialogue with Social Theory. The confrontation between theory and empirical studies allowed the emergence of categories and thematic axes that configured the results of their analysis, circumscribed in the educational relationships with children. The analysis resulting from the dialogue between the two researches (BUSS-SIMÃO, 2012; LESSA 2019) announces the categories generational relations (LESSA, 2019); 'generationing' processes; generational order (ALANEN, 1994; 2001; 2012); gender boundaries; neutralization (THORNE, 1993), and; inter
\end{abstract}

\footnotetext{
${ }^{1}$ Universidade do Estado de Santa Catarina (UDESC). Florianópolis, SC, Brasil. < julianallessa@gmail.com>

${ }^{2}$ Universidade Federal de Santa Catarina (UFSC). Florianópolis, SC, Brasil. <marcia.simao@email.com.br> Educação em Revista|Belo Horizonte|v.37|e25804|2021
} 
and intragender relations (KELLE 1997, 1999, 2000) as important contributions to the critical analysis of the educative-pedagogical practice in Early Childhood Education.

Keywords: Early Childhood Education, generational processes, gender relations, care, children.

\section{GÉNERO Y GENERACIÓN: DIMENSIONES DEL CUIDADO EN LAS RELACIONES EDUCATIVAS EN LA EDUCACIÓN INFANTIL}

RESÚMEN: Este artículo es el resultado de dos investigaciones etnográficas con niños, realizadas en contextos públicos de Educación Infantil. Tiene como objetivo analizar las relaciones entre las dimensiones del cuidado, género y generación, desde el marco teórico correspondiente a los principales referentes utilizados en las investigaciones, como los Estudios Sociales de la Infancia, en diálogo con la Teoría Social. El enfrentamiento entre teoría y datos empíricos permitió a las investigaciones el surgimiento de categorías y ejes temáticos que configuraron los resultados de su análisis, entre los cuales se eligieron para la discusión categorías de cada investigación, ambas circunscritas en las relaciones educativas con los niños. El análisis resultante del diálogo entre las dos investigaciones (BUSS-SIMÃO, 2012; LESSA, 2019) anuncia las categorías relaciones generacionales (LESSA, 2019); procesos de generacionalización; orden generacional (ALANEN, 1994; 2012); fronteras de género; neutralización (THORNE, 1993) y; las relaciones inter e intragénero (KELLE 1997, 1999, 2000) como importantes aportes al análisis crítico de la práctica educativo-pedagógica en la Educación Infantil.

Palabras clave: Educación Infantil, procesos generacionales, relaciones de género, cuidado, niños. 


\section{O CUIDADO NA EDUCAÇÃO INFANTIL: RELACÕES GERACIONAIS E DE GÊNERO}

Neste texto, apresentamos uma reflexão sobre os processos educativos de crianças pequenas em contextos coletivos de Educação Infantil, a partir de duas ${ }^{3}$ pesquisas que tomaram as relações de gênero e geracionais ${ }^{4}$ como categorias de análise para pensar sobre a dimensão corporal (BUSS-SIMÃO, 2012) e da alimentação (LESSA, 2019), que são constitutivas das relações pedagógicas. Consideramos que as categorias abordadas nas pesquisas são centrais para a compreensão das relações de cuidado, como uma especificidade das relações educativas na Educação Infantil e, sobretudo, como uma relação fundante da infância, caracterizada pela interdependência das crianças em relação ao mundo adulto para garantir a produção de sua existência.

Nessa direção, nossos propósitos com este artigo buscam acentuar a dimensão pública do cuidado, considerando um debate que se inscreve na defesa por políticas de combate às estruturas de opressão que configuram as desigualdades de acesso e produção do cuidado na nossa sociedade. Indicamos também a defesa por garantia das condições materiais e concretas de acesso igualitário a essas políticas, levando em conta as singularidades de cuidado que os distintos grupos sociais demandam (crianças, jovens, pessoas idosas, aquelas com necessidades específicas, populações negras, de mulheres, imigrantes, indígenas, quilombolas, ribeirinhas, para citar alguns exemplos). Trata-se de considerar as diferentes demandas das políticas de cuidado, partindo do pressuposto de que as desigualdades de acesso a essas políticas são reprodutoras das desigualdades sociais.

No caso da pequena infância, a política do cuidado encontra-se ora na esfera da assistência, ora na da educação, colocando aí a necessidade de pensarmos no cuidado enquanto política intersetorial, ou seja, que necessita ser entendido em suas múltiplas facetas: cuidado à saúde, educação e a assistência que, no caso da criança pequena, é transversal a toda e qualquer forma de interação em que estejam envolvidas. A Educação Infantil pública brasileira, atrelada às políticas de cuidado e proteção social da infância, incluindo as de alimentação, foram caracterizadas muito mais pela assistência e pela produção e reprodução da pobreza, como se viu no período ditatorial, nas décadas de 1960 a 1980 (VIEIRA, 1988; KUHLMANN JR, 1991; ROSEMBERG, 2002).

Posteriormente, com a abertura do regime, essas políticas expandiram o atendimento como políticas públicas, garantindo sua conquista como direitos sociais, pós Constituição Federal (BRASIL, 1988), o que resultou em uma ampliação numérica, porém sem alcançar uma universalização do atendimento e da qualidade. Entretanto, a partir deste marco, o acesso às instituições públicas de Educação Infantil passou a ser um direito social das crianças e suas famílias, cujo dever compete aos municípios e à esfera federal. Também, a expansão de vagas permite vislumbrar, diferentemente da reprodução da pobreza, o aumento e fortalecimento de uma classe trabalhadora disposta a disputar a Educação Infantil e, portanto, a operar sobre a transformação política do cuidado.

A coexistência entre instituições públicas e privadas e também entre Organizações NãoGovernamentais (ONGs), de origem filantrópica, por sua vez, é geradora das desigualdades de classe que, historicamente, estiveram vinculadas ao surgimento das creches e pré-escolas. Essas desigualdades relacionam-se com os modos de conceber as atividades ligadas ao cuidado de crianças, sendo essas concepções produto das condições históricas e materiais de surgimento da Educação Infantil, vinculadas às relações desiguais de gênero na sociedade. O fato de as relações de cuidado serem socialmente vinculadas a regras e normas de gênero, as produzem como conjunto de atividades femininas e, portanto, dentro de um universo socialmente construído pelas e para as mulheres. Ao naturalizar o papel da mulher nessas ações, tanto no trabalho doméstico (incluindo o trabalho mental) ${ }^{5}$ como no trabalho remunerado,

\footnotetext{
${ }^{3}$ Pesquisas em nível de Doutorado realizadas no âmbito do Núcleo de Estudos e Pesquisas da Educação na Pequena infância (NUPEIN/UFSC), sob orientação da Prof. ${ }^{a}$ Eloisa Acires Candal Rocha.

${ }^{4}$ Relações de gênero com base em Thorne (1993) e Ferreira (2002a; 2002b); e relações geracionais com base em Alanen (1994; 2012).

${ }^{5}$ Conforme explicam Castro e Chaguri (2020, s/p.), "Em meados dos anos 1980, Monique Haicault cunhou a ideia de "carga mental" para descrever o constante cansaço sentido pelas mulheres que se inseriam no mundo do trabalho. Haicault teve larga experiência de pesquisa com mulheres que trabalhavam a domicílio na indústria têxtil, sobrepondo espaços e tempos de trabalho. Entretanto, quando a pesquisadora deslocou seu estudo para outro contexto, o de mulheres trabalhando em fábricas, fora de casa, percebeu como a distinção de espaços sociais era simplesmente de ordem simbólica. Quando estão nas fábricas, Educação em Revista|Belo Horizonte|v.37|e25804|2021
} 
o cuidado passa a ser engendrado a partir do que Helena Hirata $(1997 ; 2002 ; 2005 ; 2009)$ e Danièle Kergoat (2009) conceituam como divisão sexual do trabalho, definido no Dicionário Crítico do Feminismo $^{6}$ (HIRATA et al. 2009, p. 67) por Kergoat (2009) da seguinte forma:

[...] as condições em que vivem homens e mulheres não são produtos de um destino biológico, mas, sobretudo, construções sociais. Homens e mulheres não são uma coleção - ou duas coleções - de indivíduos biologicamente diferentes. Eles formam dois grupos sociais envolvidos numa relação social específica: as relações sociais de sexo. Estas, como todas as relações sociais, possuem uma base material, no caso o trabalho, e se exprimem por meio da divisão social do trabalho entre os sexos, chamada, concisamente, divisão sexual do trabalho.

O cuidado, enquanto relações inscritas na divisão sexual do trabalho (HIRATA, 1997; 2002; 2005; 2009; HIRATA e KERGOAT, 2007; KERGOAT, 2009), além de marginalizado, é sustentado pela dupla ou tripla jornada das mulheres, ou seja, pela soma de trabalho produtivo, remunerado e reprodutivo, não remunerado. No contexto da Educação Infantil, essas questões se intensificam, pois o cuidado não está apenas presente na esfera doméstica, como também, na pública. Nesse sentido, a lógica da extensão do cuidado doméstico com as crianças para a Educação Infantil tem consolidado essa etapa da educação básica como um espaço ocupado, em sua enorme maioria, por mulheres (CERISARA, 2002; VIANNA, 2013). Ao sermos socialmente produzidas para nos preocuparmos com aqueles que cuidamos em nosso universo feminino (e não apenas maternal), também nos dedicamos a pensar sobre as sensibilidades e a heterogeneidade das crianças no contexto educativo. Assim sendo, à carga mental do cuidado com a família e afins, adiciona-se a do cuidado no espaço de trabalho.

Compreendemos as relações de cuidado, no contexto da Educação Infantil, como uma atividade profissional realizada por pessoas adultas habilitadas, para todas as crianças, garantindo suas distintas demandas e demarcadas as garantias de condições materiais. Isso implica retirar o cuidado da esfera doméstica, reforçando a importância do cuidado, da dimensão corporal e das práticas de alimentação que residem tanto na sua inevitabilidade como na sua dimensão política, por se constituir em um sistema de produção material e simbólico em que se produzem os modos de viver a infância. Nesse sentido, problematizamos as desigualdades de gênero (incluindo raça/etnia e classe) que circunscrevem as concepções, práticas e relações de cuidado na infância.

Ambas as pesquisas (teses de doutorado) que trazemos para discussão foram desenhadas como investigações etnográficas com crianças (CHRISTENSEN e JAMES, 2005; GRAUE e WALSH 2003; SARMENTO, 2003), que têm como particularidade, além da utilização de procedimentos etnográficos, como a observação participante e a descrição densa das relações estabelecidas entre pesquisador/a e sujeitos que fazem parte do campo de suas pesquisas, o fato das crianças serem consideradas informantes privilegiadas de conhecimento sobre elas. Assim concebê-las não significa, conforme pontuou Cerisara (2004), negar a existência de patamares diferenciados entre crianças e adultos mas, pelo contrário, revela-se como um ponto de partida nos estudos da infância não apenas interessante, como necessário para balizar a ação educativa.

As duas pesquisas partiram do pressuposto de que conhecer as crianças em seus contextos reais de vida e compreender as múltiplas determinações que recaem sobre as condições de existência da infância, constituem-se em pontos de partida para a elaboração de indicadores para a prática pedagógica e de contribuições para a construção de uma Pedagogia da Infância ${ }^{7}$ (FARIA, 1999; ROCHA, 1999).

as mulheres planejam a vida doméstica, pensam sobre as compras da semana e do mês, as contas a pagar e as tarefas que têm para cumprir. A casa as acompanharia à fábrica. A carga mental não está, portanto, na justaposição ou somatória de atividades, mas na sua sincronicidade, na sua simultaneidade. [...]. A carga mental está cheia desses pequenos censores que dizem de maneira simples e tão frequente: 'Não tenho tempo"” (HAICAULT, 1984, p. 275, tradução livre de CASTRO e CHAGURI, 2020).

"Verbete: “divisão sexual do trabalho e relações sociais de sexo”, Dicionário Crítico do Feminismo (HIRATA et al.) 2009, p. 67).

${ }^{7}$ Conforme a definição feita por Barbosa (2010), no verbete Pedagogia da Infância: "Pedagogia da Infância emerge de uma acumulação científica da área da educação que passa a criticar a reprodução de modelos educativos reducionistas e conservadores de educação/ensino, produção/transmissão de conhecimentos, vida coletiva/sala de aula e crianças/alunos. Rocha (1999) e Faria (1999) indicaram, a princípio, a Pedagogia da Infância como uma perspectiva de educação pública para a Educação Infantil, porém, a seguir, estenderam-na para todos aqueles que estão entre 0 e 10 anos de vida. Afirma a infância Educação em Revista|Belo Horizonte|v.37|e25804|2021 
Pedagogia esta "ainda não consolidada a ponto de orientar claramente a formação e as práticas educativas” (ROCHA, LESSA e BUSS-SIMÃO, 2016, p. 39). O quadro teórico corresponde às referências que as duas pesquisas (BUSS-SIMÃO, 2012; LESSA, 2019) utilizaram, conforme será apresentado adiante, fundamentadas em perspectivas dos Estudos Sociais da Infância, no diálogo com a Teoria Social.

Tanto a pesquisa de Buss-Simão (2012), como a de Lessa (2019) foram realizadas em instituição pública e urbana de Educação Infantil de tempo integral, cada qual pertencente a uma mesma Rede Municipal de Ensino de uma capital localizada na Região Sul do Brasil. Buss-Simão (2012) observou e registrou, por meio escrito, fotográfico e de vídeo, durante os meses de março a novembro do ano de 2009, de 2 a 3 vezes por semana, as relações estabelecidas entre crianças com foco sobre sua dimensão corporal, em um grupo etário, formado por 15 crianças, entre 2 e 3 anos, sendo 12 meninas e 3 meninos. As observações participantes e registros da descrição densa ocorreram nos diversos espaços e tempos pedagógicos que configuram a rotina de tempo integral da Educação Infantil (momentos de alimentação, parque, sala, sono, higiene). Já na outra pesquisa, Lessa (2019) registrou, também por meio escrito, fotográfico e de vídeo as relações estabelecidas entre e com as crianças durante suas práticas de comer coletivamente no espaço de um refeitório de uma instituição de Educação Infantil. Durante 9 meses, a pesquisadora participou, em dias e momentos alternados, dos diferentes momentos de refeições que estruturam a rotina de tempo integral (café da manhã, almoço, lanche da tarde e janta), acompanhando um coletivo formado por 210 crianças $^{8}$, entre 1 e 6 anos, matriculadas na instituição no ano em que a pesquisa de campo foi realizada (2016). Também compuseram os dados das duas pesquisas etnográficas, conversas semiestruturadas com profissionais das equipes pedagógicas e com familiares das crianças, além da análise de documentos norteadores das práticas e relações educativas, nos contextos investigados.

$\mathrm{Na}$ sequência, apresentamos, nas duas próximas seções, cada uma das duas pesquisas, destacando alguns dos conceitos operados para analisar as relações e práticas das crianças envolvendo dimensões do cuidado, quando em contextos coletivos e pedagógicos da primeira etapa da educação básica, que abrange as crianças de 0 até 5 anos e 11 meses de idade.

A primeira pesquisa que será apresentada foi a Tese de Doutorado defendida por Lessa, no ano de 2019', na qual destacamos como os conceitos de relações geracionais (LESSA, 2019); processos de geracionalização e ordem geracional (ALANEN, 1994; 2012) permitem analisar as relações de cuidado entre crianças e entre elas e adultas/os, na intesecção com a categoria geração, na qual se constrói socialmente a infância, não isolada de outras categorias, sendo as relações geracionais determinadas não apenas por recortes de idade, mas por marcadores da experiência social. Neste sentido, Lessa (2019) nos mostra como o cuidado e a educação no contexto da Educação Infantil podem ser analisados à luz das relações geracionais, a partir de uma perspectiva relacional.

A segunda pesquisa a ser apresentada trata-se da Tese de Doutorado de Buss-Simão, concluída no ano de 2012 que, ao operar com os conceitos de fronteiras de gênero e neutralização (THORNE, 1993), revela como as crianças trabalham cultural e socialmente essas fronteiras nas relações inter intragênero (KELLE 1997, 1999, 2000). Tais conceitos permitem destacar o caráter transgressor e de resistência dos agenciamentos das crianças em seus modos próprios de trabalhar as fronteiras, entre eles, por meio de processos de neutralização de relações de gênero.

Fechamos a apresentação das duas pesquisas reforçando o diálogo entre os conceitos e as categorias tomadas para análise, no intuito de contribuir para uma reflexão multidimensional das relações

\footnotetext{
como uma categoria geracional, social e histórica e geograficamente construída, heterogênea, atravessada pelas variáveis de gênero, classe, religião e etnia. Tomando como pressuposto que toda apropriação cultural e qualquer aprendizagem é resultado de uma relação social e partilhada de significados coletivos" (Dicionário: trabalho, profissão e condição docente, GESTRADO/UFMG, 2010).

${ }^{8}$ Para um maior detalhamento sobre os sujeitos participantes das pesquisas que aqui estamos apresentando, ver: Lessa (2019), Capítulo 4, item: "As crianças, famílias e profissionais da creche investigada" e Buss-Simão (2012), Capítulo II, item: “O contexto investigativo".

9 Ambas as pesquisas, de Lessa (2019) e de Buss-Simão (2012) foram realizadas junto ao Programa de Pós-Graduação em Educação da Universidade Federal de Santa Catarina e contaram com financiamento CAPES, CNPq e DAAD.

Educação em Revista|Belo Horizonte|v.37|e25804|2021
} 
pedagógicas, particularmente, aquelas de cuidado e educação, que cumprem a função social da Educação Infantil, configurando a especificidade do contexto educativo na primeira etapa da educação básica.

\section{DIMENSÕES DA ALIMENTAÇÃO NA EDUCAÇÃO INFANTIL: PROCESSOS GERACIONAIS NAS RELAÇÕES DE CUIDADO}

A pesquisa de Lessa (2019) se propôs a investigar como determinantes materiais e simbólicos atuam sobre as relações sociais das crianças, mediadas pelas práticas do comer que são, por sua vez, intrínsecas às relações de educação e cuidado que constituem as práticas pedagógicas no contexto da Educação Infantil. A pesquisa toma o espaço-tempo da alimentação das crianças, compreendido em suas condições materiais e práticas sociais como um fenômeno social de múltiplas dimensões, que a torna um sistema de produção simbólico multifacetado (BEARDSWORTH; KEIL, 1997).

Os dados ${ }^{10}$ foram analisados tomando como base os Estudos Sociais da Infância a partir da perspectiva apontada por Qvortrup (1994; 2005) acerca da infância como uma estrutura geracional, e da abordagem relacional proposta por Alanen (1994; 2001; 2012; 2014). Essa autora parte de uma análise relacional da infância como categoria geracional, no diálogo com a teoria sociológica de Pierre Bourdieu (1996; 2002; 2014) focando, sobretudo, na perspectiva relacional construída pelo sociólogo. Na tentativa de romper com um modo de pensar substancialista, que apreende estaticamente os fenômenos, Bourdieu (1996) propõe uma filosofia da ação concebida como relacional, pelo fato de atribuir primazia às relações e, também, chamada de "disposicional, que atualiza as potencialidades inscritas nos corpos dos agentes e na estrutura das situações nas quais eles atuam ou, mais precisamente, em sua relação" (BOURDIEU, 1996, p. 10 - grifos do autor). A infância, entendida como uma geração inscrita em uma estrutura de relações geracionais, exige que se preste atenção aos processos pelos quais as estruturas geracionais são constituídas e posteriormente, reproduzidas ou transformadas, o que Alanen (2012) chamou de processos de geracionalização. Compuseram essa base teórica também os estudos que tomaram como referência de campo empírico das suas pesquisas, as práticas e relações coletivas de comer das crianças em contextos educativos.

As análises gerais desta produção científica sobre o tema, formada, em sua grande maioria por pesquisas estrangeiras (línguas anglo-saxã e francófona) ${ }^{11}$, apontaram o espaço do comer na Educação Infantil como um contexto de aprendizagens e de intensa produção, entre as crianças, das mais variadas formas de sentidos vinculadas ao cuidar - ser cuidado, cuidar de si, nutrir-se e cuidar do outro - e vinculadas às especificidades que caracterizam o comer-juntos (ALCOCK, 2007) no coletivo de crianças, como um meio de cuidado (DORRER et al., 2010) e de expressão das emoções (EMOND, MCINTOSH, PUNCH, 2014). Nesse sentido, o contexto da alimentação na Educação Infantil configura-se como "um observatório das culturas infantis e das relações intergeracionais" (MATHIOT, 2012), de dinâmicas inerentes às relações geracionais (LESSA, 2019), ou seja, onde é possível observar como infância e adultez se co-constroem (ALMEIDA et al., 2013), mediadas por processos geracionais.

Pensar as relações geracionais significa atentar para as diversas formas que podem assumir, tais como as de parentalidade, de cuidado, de educação, incluindo-se diferentes agenciamentos, como criançapai/mãe, criança-professor/a, criança-grupo de pares, criança-sujeito da relação educativa, criança-sujeito das relações de cuidado, etc.

De acordo com Alanen (2012, p. 06, tradução livre de LESSA, 2019, p. 44 - grifos nossos):

[...] o significado principal da noção de uma ordem geracional é que ela dá um nome e conteúdo sociológico aos processos através dos quais o mundo social é organizado em termos de distinção geracional [...]. Para o caso das crianças, isso significa que suas vidas, experiências e significados não são apenas generificadas, classificadas, racializadas (e assim por diante), mas também - e, mais importante, para o estudo sociológico da infância - geracionalizadas ${ }^{12}$.

\footnotetext{
${ }^{10}$ Pesquisa aprovada junto ao Comitê de Ética em Pesquisa com Seres Humanos da Universidade Federal de Santa Catarina. Parecer 1.513.055 / CAAE: 54562316.0.0000.0121.

11 Turner, Mayall e Mauthner (1995); Christensen (2003); Alcock (2007); James, Kjorholt e Tingstad (2009); Comoretto (2017).

Para um levantamento detalhado da literatura internacional acerca do tema, ver o Capítulo 2 da Tese de Lessa (2019).

12 No original, generational order e generationed (ALANEN, 2012, p. 06). 
Nessa perspectiva, situar as relações geracionais como categoria de análise das relações e práticas sociais das crianças, no contexto coletivo e pedagógico da Educação Infantil significa, ao invés de tomar como ponto de partida as categorias geracionais (infância e adultez), atentar para as dinâmicas de relações que as constroem: como as idades são construídas nas-relações entre gerações e dentro das gerações (relações intergeracionais e intrageracionais). Ou seja, olhar para as relações de interdependência mútua pelas quais adultas/os e crianças se tornam quem são, superando o caráter "estático", atribuído às categorias infância e adultez. Nesta direção, uma criança torna-se uma criança concreta e situada à medida em que assim se faz na relação com um outro e dentro de um mundo adulto material e simbólico particular: um/a filho/a vai assim se tornando filho/a na relação de cuidado envolvendo a parentalidade com adultas/os.

Tratar sobre os processos geracionais como uma dimensão das relações educativas na infância significa evidenciar os dados a partir da construção analítica de uma ordem geracional, no caso da pesquisa de Lessa (2019), construída no espaço-tempo reiterativo e pedagógico das práticas do comer das crianças na Educação Infantil. Para tanto, as análises dos dados foram apresentadas na pesquisa, conforme a interpretação das lógicas etárias de funcionamento do comer na creche, ou seja, a construção de ordens geracionais distintas. No campo investigado, o refeitório ${ }^{13}$ consistiu no principal contexto de observação, sendo, nesse espaço pedagógico, diariamente servidas as refeições, mediadas por adultas de diferentes equipes: pedagógica, de nutrição, da cozinha e de limpeza. A ordem geracional foi construída a partir da evidência de uma organização social (com seus conflitos e contradições) em termos de distinções etárias: formas diferentes de se pensar e organizar os momentos do comer, requerendo das crianças certas competências, conforme os grupos etários; mas também, formas diferentes de organização desses momentos, requerendo de crianças de mesma faixa-etária competências e ações diferentes. Isso nos mostra como as idades das crianças e tornar-se criança vão sendo construídas nas dinâmicas de relações geracionais.

Nesse sentido, uma questão a se considerar, ao tomarmos as relações geracionais como categoria de análise, é que a infância não se define apenas em termos de idade, mas também, de experiência social. Um exemplo observado na pesquisa foi a identificação de construções de práticas geracionais distintas para grupos de mesma faixa etária. No caso, por exemplo, de dois grupos de mesma faixa-etária, porém, um formado por crianças novatas e outro por veteranas na experiência social da instituição, as competências e capacidades de ação esperadas no refeitório eram diferentes. Isso significa que as relações geracionais não se constroem apenas pelos recortes de idade, mas de uma idade social.

Nessa mesma direção, Wintersberger (2005) observa que a infância como categoria geracional e as suas relações entre idades podem ser explicadas tomando como base as relações de gênero. Embora suas relações sejam de natureza diferente, o autor mostra que, tanto as relações de gênero não se constroem apenas pelo sexo, como as relações geracionais não se constroem apenas pelas idades:

Enquanto pesquisadores feministas introduziram a dimensão do sexo para revelar a ordem de gênero patriarcal dos welfare states, a dimensão geracional na pesquisa sobre a infância é, em princípio, sobre a idade. Mas, como no caso do sexo e do gênero, devemos fazer uma distinção entre idade biológica e social como ordem geracional da sociedade. Embora a idade biológica possa ser facilmente definida até o dia do nascimento, o significado social de ser, por exemplo, de 17 anos varia de acordo com o nacional e o cultural, bem como por diferentes períodos da história (WINTERSBERGER, 2005, p. 228, tradução livre de LESSA, 2019, p. 44-45).

O trecho do registro de campo (LESSA, 2019), a seguir, possibilita observar as dinâmicas inerentes às especificidades das relações geracionais que o contexto pedagógico do compartilhar a refeição à mesa permite, particularmente, de relações entre crianças (relações intrageracionais):

\footnotetext{
13 Outros espaços, além do refeitório, compuseram as observações e registros, por se tratarem de outros contextos nos quais a pauta da alimentação figurava na dinâmica pedagógica da instituição. Foram eles: reuniões pedagógicas e eventos com a participação das crianças e suas famílias, reuniões com famílias e bebês, além de espaços como as salas dos grupos (incluindo a dos bebês) e os parques, que se configuram como espaço-tempo de interações e relações anteriores e posteriores àquelas presentes nas relações inter e intrageracionais no refeitório.
} 
Camila (5-6 anos) compartilha a mesa com um menino do mesmo grupo que o seu e outro menor (3-4 anos). Passo a observá-los. O menino do mesmo grupo pergunta à Camila: "Tu vais comer mais?". Ela responde afirmativamente e começa a dialogar com o menino pequeno, que está sentado a sua frente. Sem que verbalizem palavras entre si, Camila mostra a sua própria blusa para o pequeno. Ele a observa e tenta entender o gesto da menina. Agora, ela pega em sua própria blusa e faz um gesto de sacudi-la. Ele demora a entender. Então, ela se debruça sobre a mesa e tira o arroz que havia na blusa dele. "Ele só come tomate em casa", diz Camila para mim. "Que esquisito isso né?!", continua a menina. Camila se levanta e vai repetir a refeição, deslocando-se ao buffet junto com o amigo que perguntou se ela iria comer mais (LESSA, 2019, p. 239 - Registro de campo de 15/06/2016/Almoço).

No episódio, é possível observar como as crianças, nas suas dinâmicas de relações, articulam processos geracionais, tal como o cuidado da menina mais velha com o menino mais novo, dentro de uma particularidade própria da relação geracional observada (criança mais nova e criança mais velha). Enquanto o menino nos mostra seus processos de apropriação das práticas culturais mais essenciais, mediados pelas relações intergeracionais (entre gerações), como comer com a colher, sentar-se à mesa e compartilhar a refeição com os pares, é na sua relação com a menina mais velha que podemos ver como ocorrem os processos de geracionalização ${ }^{14}$ (ALANEN, 1994; 2001). A análise trazida na pesquisa revela o caráter contraditório e de natureza conflitual das relações geracionais, particularmente aquelas envolvendo as relações entre crianças e adultas/os da instituição, e ainda, entre adultas/os da instituição e entre adultas/os da instituição e adultas/os familiares das crianças. Nestas relações, diferentes adultas/os requerem diferentes competências para crianças de mesmo recorte etário. Por outro lado, no registro da pesquisa apresentado, ao recair a análise sobre as relações entre as crianças, elas acabam revelando outra ordem geracional, fundada em relações geracionais de natureza cooperativa e horizontalizada.

A criança mais velha, ao reproduzir suas relações intergeracionais na interação com a mais nova, também vai se fazendo mais experiente por meio desta relação. Este processo de reprodução e transformação das relações geracionais pode ser entendido como o que Alanen (2001) define como processos geracionalizados on processos de geracionalização. Estas dinâmicas revelam como o mundo adulto vai se produzindo entre os sentidos atribuídos pelas crianças e postos em relação com seus pares. Episódios como este, trazidos na pesquisa (LESSA, 2019) mostram que uma das especificidades do comer-juntos consiste no fato de que as crianças, companheiras à mesa, também educam outras crianças, sendo estas relações, portanto, objeto de reflexão da ação pedagógica.

No episódio, as culturas infantis, nomeadamente a produção coletiva de sentidos, que se dá mediada pelas práticas do comer das crianças no contexto pedagógico, revela sua composição de relações cooperativas. Nele, é possível observar como o comer-juntos, que caracteriza as relações entre as crianças à mesa, possibilita expandir um cuidado de si para outrem, em uma ação de sentido cooperativo com o outro. A menina, ao expressar competências de cuidado consigo, vinculadas às suas práticas do nutrir-se, potencializa essas práticas de si com o outro, na relação com o menino mais novo que, ao que parece, possui certa intimidade, já que faz menção a uma curiosidade acerca dele, observada "em casa". Essa ação de cuidado com a criança mais nova ocorre em relação à sua ação em si, de limpá-lo, mas também com a expressão de uma norma e, por último, de um modo de falar sobre o menino mais novo, na terceira pessoa do singular, sem referir-se diretamente a ele. Quando a menina ajuda o menino mais novo a limpar-se, primeiro, tentando lhe mostrar, por meio de gestos, o arroz que tinha caído sobre sua blusa, depois, ela mesmo ajudando-o a sacudir a blusa, até que caíssem os vestígios de comida, faz isso com discrição, sem expor o menino e sem verbalizar com ele. E faz também verbalizando para a pesquisadora acerca de uma questão alimentar do menino, manifestando esse outro da relação como um sujeito/objeto de preocupação: "que esquisito isso né?". Essas dinâmicas de relações mostram como a menina vai se tornando mais experiente na relação com a mais nova e, como a própria criança mais nova vai se tornando mais experiente na relação com a mais velha, revelando processos geracionalizados nas relações entre as crianças potencializadas nos momentos de alimentação no coletivo da Educação Infantil.

Essa potencialidade de relações intrageracionais, mediadas por práticas de cuidado, como a de alimentação, se dá não apenas pelo contexto em si, que reúne um coletivo de crianças, mas também

\footnotetext{
14 No original, generationing process (ALANEN, 2001, p. 130), que consistiria em processos geracionalizados ou de geracionalização.
} 
pelo fato de que a comida, em contexto de creches e pré-escolas, se apresenta às crianças como um conjunto de práticas sociais e culturais desprovidas e protegidas dos valores do mercado, com um valor em si mesma, resguardando uma proteção alimentar. Faz parte da organização e gestão da educação básica, pública e brasileira, o Programa Nacional de Alimentação Escolar (PNAE, 2013), que garante às crianças da Educação Infantil, a oferta de quatro a cinco refeições, quando estão na jornada de tempo integral. Como parte de uma política de cuidado da infância, inscrita na política educacional, a alimentação no contexto de creches e pré-escolas garante uma relativa proteção da infância aos ditames do mercado, sobretudo nos modos de se relacionar com a comida, sem a mediação da publicidade e propaganda e da comida como mercadoria, sendo potencializada a partir de outras, como as interações com os pares e as relações de cooperação e cuidado horizontais que delas derivam, como se pôde ver.

$\mathrm{Na}$ construção do quadro relacional de análise da pesquisa (LESSA, 2019), que incluiu a identificação das relações a serem pesquisadas, a atenção foi direcionada para os processos geracionais que se evidenciavam nas dinâmicas de relações educativas, possibilitadas pelas diversas formas de relações geracionais que se configuram no contexto das práticas do comer das crianças na rotina da Educação Infantil. Um exemplo disso pode ser observado na análise dos processos geracionais abrangendo as relações entre crianças mais novas e adultas/os da equipe pedagógica. Situações trazidas na pesquisa em que algumas crianças mais novas recebem comida na boca são reveladoras de um descompasso de tempos distintos (institucional, biológico, social e cultural), que se chocam com a experiência do comer, e que vai sendo mediado pelas relações intergeracionais (entre adultez e infância). Dar a comida na boca da criança, de um modo geral, permite orquestrar o tempo da experiência individual com aquele do comer-juntos, com o tempo da rotina educativa, incluindo os horários de entrada e saída da equipe pedagógica, e aquele cronometrado, que marca o tique-taque das refeições do coletivo.

Em contrapartida, o dar a comida na boca, como uma ação geracional que traz consigo o controle de tempo lento/apressado, também designa uma relação de cuidado. Nessa relação assimétrica que se instaura, entre o adulto que dá a comida na boca e a criança que recebe o alimento, a linguagem verbal, como um modo estratégico de estabelecer relações de cuidado, se coloca como central nos sentidos pedagógicos da ordem geracional. Uma recusa de uma colher à boca pode ser verbalizada pela pergunta se a criança está satisfeita, ainda que ela não entenda em um primeiro momento; posteriormente, entenderá que a indagação é chave para expressar processos de autocuidado (saciedade ou o seu apetite), os quais são constitutivos da dimensão corporal presente nas relações educativas na Educação Infantil. Isto revela a importância de referenciais simbólicos que proponham a aposta em uma relação pedagógica voltada para a negociação de sentidos e acordos, espelhada nas formas horizontais e cooperativas refletidas nas relações geracionais observadas entre as crianças, o que sugere mais uma posição interessada, do que propriamente de comando, potencializando a reflexividade das crianças e o compartilhamento de significados entre elas e com adultas/os (GARNIER e RAYNA, 2017, p. 11).

Por fim, um último ponto a ser destacado da pesquisa de Lessa (2019) e que consideramos uma contribuição para o debate das relações pedagógicas na Educação Infantil, se relaciona ao fato de que, no campo investigado ${ }^{15}$, as práticas cotidianas de alimentação estão inscritas em um projeto políticopedagógico, práticas essas que dão contornos para se pensar o cuidado em sua dimensão políticopedagógica. Nesse sentido, a importância que o comer tem nos contextos coletivos de Educação Infantil relaciona-se tanto a um sentido elementar do nutrir para se manter vivo, quanto a um sentido social e, portanto, educativo e pedagógico ${ }^{16}$. A própria vida somente pode ser pensada dentro da nutrição do corpo; viver, significa nutrir o corpo.

Esse cuidado é tão vital e fisiológico que acentua sua dimensão política à medida em que pensamos como ele é regulado e concebido por todas/os e para todas/os. Percebemos isso quando prestamos atenção a quem são as crianças mais afetadas pelo isolamento social por conta dos riscos de contaminação pela pandemia do novo Coronavírus (COVID-19), que assola o Brasil e o mundo desde o

\footnotetext{
${ }^{15}$ Conforme Projeto Político Pedagógico da instituição investigada (PPP, 2016).

${ }^{16}$ A distinção entre educativo e pedagógico aqui tem como referência a ideia de que um cuidado pode ser educativo, como os cuidados vinculados à família, mas isso não significa que ele seja pedagógico, pelo fato deste último conter em si a ideia de uma ação pensada, intencionalmente planejada e avaliada. 
início do ano de $2020^{17}$, com o fechamento das instituições educacionais e a interrupção do atendimento presencial e coletivo às crianças. Todas são afetadas porque interrompem processos educativos importantes mas, outras, porque deixam de ter acesso a uma política nacional de alimentação gratuita e balanceada, que cumpre sua função a partir do atendimento diário às necessidades do corpo, com a garantia concreta das condições para o acesso às refeições e aos tipos de alimentos, dentro de uma segurança alimentar. A alimentação oferecida pelas instituições públicas de educação tem determinante impacto na soberania e segurança alimentar das crianças. Uma das primeiras reivindicações às instâncias municipais, estaduais e federal, com a impossibilidade do atendimento em creches, pré-escolas, escolas e universidades, por conta do isolamento social e dos riscos de uma contaminação pandêmica, foi pela garantia da continuidade ao acesso à alimentação, por meio de auxílios financeiros ou de distribuição da alimentação.

Se a pesquisa de Lessa (2019), ao investigar as relações das crianças no contexto coletivo das práticas do comer, à luz a categoria geração, chama atenção para as relações geracionais como uma das dimensões constitutivas do cuidado, este, por sua vez, fundante dos processos pedagógicos na Educação Infantil, o estudo de Buss-Simão (2012) toma como categoria de análise as relações de gênero como uma das dimensões constitutivas do corpo, ao focar nas relações das crianças com seus pares, no contexto coletivo da Educação Infantil. Como veremos, o diálogo entre as duas pesquisas evidencia as categorias gênero e geração como importantes dimensões para pensar a especificidade do cuidado nas relações e práticas nesses contextos, estando intrinsecamente ligado aos demais determinantes sociais de classe e etnia/raça.

\section{GÊNERO E CUIDADO NAS RELAÇÕES EDUCATIVAS NA EDUCAÇÃO INFANTIL}

A pesquisa de Buss-Simão (2012), investigou como as crianças pequenas expressam, manifestam, compartilham e dão significados a elementos culturais e sociais envolvendo o corpo, apresentando a categoria gênero como uma das dimensões constitutivas das relações educativas na Educação Infantil.

Para as análises destas relações entre as crianças e delas com as/os adultas/os, Buss-Simão (2012), fundamentada em Thorne (1993) e Kelle $(1997,1999,2000)$ conduziu a pesquisa observando não somente as relações de gênero em grupos separados por sexo (relações intergêneros), mas também as variações e as relações dentro do mesmo gênero (relações intragêneros). Essa perspectiva busca superar o dualismo existente entre o mundo das meninas e o mundo dos meninos, pois, quando as relações de gênero são analisadas somente em contraposição (intergêneros), podem desencadear ideias e suposições caricaturadas, reforçando o que é específico de um ou de outro, considerando, a priori, as diferenças entre gêneros mais importantes do que as diferenças no interior dos gêneros (intragêneros).

$\mathrm{Na}$ aproximação aos sentidos dados pelas crianças a seus modos de vida no coletivo educacional, a categoria gênero foi se delineando como central e constitutiva de suas relações e interações. Buss-Simão (2012) mostra que a separação, observada entre meninas e meninos, no contexto das relações e interações da Educação Infantil constitui uma espécie de trabalho de fronteiras ${ }^{18}$ (THORNE, 1993), mais fortemente sentido, no âmbito das interações entre pares, por aquelas crianças que desejam participar de uma atividade controlada por crianças de outro sexo. Entretanto, essas fronteiras, pelo fato de serem trabalhadas pelas crianças, podem também se dissolver em outros contextos de interações e relações no espaço coletivo da Educação Infantil, fato que atribui a essas fronteiras um caráter episódico, multifacetado e contraditório.

O termo trabalho de fronteiras deriva da análise do antropólogo social Fredrik Barth (1969), em que o autor conceitua aquelas relações sociais mantidas através de fronteiras étnicas (por exemplo, entre

\footnotetext{
${ }^{17}$ No momento de escrita e fechamento do artigo, o mundo inteiro já registrou mais de 3 milhões e 800 mil mortes, das quais mais de 500.000 mortes foram no Brasil, ocupando a segunda posição com maior número de mortes no mundo, atrás apenas dos Estados Unidos. Em 17 de janeiro de 2021, teve início as vacinações no Brasil e, até meados de junho apenas 11,2\% da população estava imunizada.

${ }^{18}$ No original, borderwork (THORNE, 1993).
} 
os sámi ${ }^{19}$ (ou lapões e noruegueses), sem diminuir o sentido dos participantes da diferença cultural e étnica. Enquanto Barth (1969) centra-se numa perspectiva macro, num regime ecológico, Thorne (1993) enfatiza as interações, tanto entre grupos, quanto entre os sujeitos de um mesmo grupo, nas quais, as percepções podem ser similares nos dois casos: “[...] embora o contato, por vezes, enfraquece e reduz um sentido ativo de diferença, os grupos podem também, por meio da interatividade com o outro, fortalecer suas fronteiras" (THORNE, 1993, p. 65 - tradução nossa). A noção de trabalho de fronteiras permite analisar as relações inter e intragênero, revelando os limites dessas relações e como as crianças são capazes de trabalhar culturalmente o gênero. Buss-Simão (2012) chama atenção para o alerta feito por Thorne (1993) quanto ao entendimento da noção de 'fronteira' que, erroneamente, pode sugerir um cercado, ou um muro inflexível, divisor de duas partes. Contrapondo esse entendimento, recomenda que a imagem de como as fronteiras são trabalhadas deveria ser semelhante a um conjunto de pequenos cercados, ou muros, que podem ser rapidamente desmontados, dissolvidos e transformados.

Ao observar essas interações, Thorne (1993) identifica quatro modos de trabalhar as fronteiras que envolve as relações entre as crianças e delas com as/os adultas/os: i) os jogos de perseguição nas relações intergênero, compostos por elementos básicos de perseguir e fugir, capturar e salvar, sendo esses um meio de assegurar a manutenção das fronteiras entre meninos e meninas; ii) as estratégias de competição, que consistem em instigar meninas e meninos uns contra os outros em competições, sendo essas potencializadas naquelas relações pedagógicas que acentuam as divisões e oposições de gênero; iii) os rituais de contaminação (mais recorrentes nos agenciamentos das meninas ${ }^{20}$ ), consistem em contaminar alguém, ou um grupo, com um vírus invisível (ou manter a imunidade ou até eliminar a contaminação) e; iv) as estratégias de invasões, nas quais meninas ou meninos, individualmente ou em grupos, perturbam, deliberadamente, as atividades controlados pelo grupo do sexo oposto, importunando ou mesmo arruinando seus jogos e suas brincadeiras.

As estratégias de invasões, como modo de trabalhar as fronteiras, foram mais comumente observadas sendo utilizadas pelos meninos, tanto nos estudos de Thorne (1993), quanto nos de BussSimão (2012). O episódio a seguir (BUSS-SIMÃO, 2012) evidencia como as crianças protagonizam estratégias de invasões e o modo como elas trabalham as fronteiras de gênero nas relações intra e intergênero com os pares.

Na casinha que há no parque, as meninas: Manu, Isa e Helena brincam. Léo, um dos meninos do grupo chega e se movimenta, tal como se fosse o homem-aranha, pendurado na casa, e as meninas, comentam:

Isa: Vamos embora?

Helena: Mas aqui é nossa casa!

Isa: Mas ele tá ali. [se referindo ao Léo]

Manu: Vai embora, Léo!

Léo fica parado na porta de entrada em pé, quase pendurado e acena negativamente a cabeça. Manu recorre a mim:

Manu: Diz para ele sair daqui! Aqui é casa só de meninas! Tu não tais vendo? Nós somos todas meninas e ele é um menino! [não tinha a intenção interferir na situação, fato que me levou a questionar Manu]:

Pesquisadora: Aqui não pode entrar menino?

Todas as meninas juntas (Isa, Manu, Helena) e agora Nicole [que acabou de chegar] dizem: Não! Manu complementa: Só o Willian!

As meninas ficam mexendo em seus potes e se perguntam: Vamos embora? Mas permanecem no local, assim como Léo, que também permanece e olha para as meninas. Em seguida, Léo entra na casa e fala:

Léo: Eu sou o papai - mas as meninas não o ouvem [ou não o querem ouvir].

Então, ele junta duas sementes e pergunta para Manu:

Léo: Que é isso, Manuele? - [acentua fortemente o nome dela juntando o apelido Manu com o nome Emanuele] mostrando as duas sementes.

Manu olha para elas e diz:

Manu: Sai daqui com essas bagas, a gente não quer nada de baga aqui! (BUSS-SIMÃO, 2012, p.

\footnotetext{
${ }^{19}$ O povo sámi, conhecido, antes de suas mobilizações etnopolíticas, também como lapões, correspondem a um dos maiores grupos indígenas da Europa.

${ }^{20}$ No grupo pesquisado por Buss-Simão (2012) não foram presenciados episódios de contaminação protagonizadas pelas meninas durante o período de pesquisa de campo. 
268 - Registro de campo de 08/06/2009).

Por não ser permitida sua entrada no grupo de meninas e, consequentemente, sua participação nas brincadeiras (pelas fronteiras de gênero por elas trabalhadas), Léo, muitas vezes durante a pesquisa, protagonizou situações em que arruína a brincadeira das meninas, seja destruindo suas produções ou tomando delas os objetos e brinquedos que utilizavam. No episódio descrito, é possível afirmar que, mesmo não havendo, a priori, uma definição de territorialidade das meninas ou dos meninos, havia uma demarcação circunscrita ao momento e à brincadeira que acontecia, por meio de relações intragênero (entre meninas). Quando o grupo de meninas brinca na casinha do parque, elas significam este espaço como um território marcado pelas relações de gênero, sendo essa compreensão manifestada pela Manu, quando solicita que a pesquisadora intervenha na invasão de Léo ao território, dizendo: “diz para ele sair daqui! Aqui é casa só de meninas! Tu não tais vendo? Nós somos todas meninas e ele é um menino!". A afirmação de Manu potencializa a compreensão do corpo como manifestação do gênero, que se desdobra em impedimento à entrada e participação no grupo de pares, pelo fato deste corpo ser de um menino.

No episódio é possível também perceber as estratégias lançadas pelo Léo, que chega e é impedido de participar da brincadeira, primeiro, atribuindo a si um papel na brincadeira, demarcado pela fronteira de gênero: "eu sou o papai", sem que haja qualquer reação de aceite por parte do grupo de meninas; depois, juntando duas sementes e perguntando de forma enfática e direta para um das meninas: "Que é isso, Manuele?". Léo, ao questionar diretamente uma das meninas acentuando fortemente o nome inteiro dela, ao invés do uso de seu apelido, busca conseguir a atenção de, pelo menos uma delas; no caso, ele se volta para aquela que expressa frequente domínio nas suas relações intragênero, liderando, na condução das brincadeiras, tomadas de decisões e papeis de prestígio. Nenhuma das estratégias do Léo têm abertura para acesso ao grupo de meninas, sendo, tanto ele, quanto as suas sementes, dispensadas com um "sai daqui com essas bagas, a gente não quer nada de baga aqui!". Este episódio selecionado da pesquisa de Buss-Simão (2012) permite constatar que a separação espacial de meninas e meninos acaba afetando mais as relações intergênero das crianças, como no caso de Léo, que deseja entrar na brincadeira do grupo de meninas. Nestes momentos, as relações de gênero como oposições são potencializadas e, apesar de meninas e meninos estarem reunidos em uma mesma territorialidade, as fronteiras trabalhadas enfatizam suas separações.

Outras formas de trabalhar as fronteiras, distintas do ritual de invasão (THORNE, 1993), agenciado por Léo, também puderam ser observadas com recorrência na pesquisa de Buss-Simão (2012), como aquelas protagonizadas pelo Willian. Representativas dessa forma de trabalhar as fronteiras foram as situações envolvendo a troca de calçados entre as crianças, presenciadas em diversas ocasiões da rotina de interações do grupo. Em muitos destes momentos, o grupo predominante de meninas posicionou-se veemente contra a participação de Willian na troca, porém, em outros, as meninas aceitam e até convidam (como veremos no outro episódio) para a troca de seus calçados, colocando em evidência como as fronteiras de gênero não são fixas, mas construídas nas relações entre as crianças:

\footnotetext{
Depois do parque, as crianças voltam para a sala, lavam as mãos e, em seguida, almoçam. As meninas se sentam no tapete e começam novamente um troca-troca de calçados. Letícia, Amanda, Manu, Nicole, Camila e Bianca estão sentadas em círculo no tapete. Willian termina de lavar suas mãos, junta-se a elas e fala:

Willian: Eu também quero trocar. Então, o menino tira suas sandálias e pega uma das meninas, mas Camila fala:

Camila: Não, esse é de menina!

Quando Willian pega outras sandálias para calçar, ela observa novamente:

Camila: Esse também é de menina!

Com a definição de Camila, Willian acaba não trocando as sandálias, fica com as suas e segue para o refeitório com elas (BUSS-SIMÃO, 2012, p. 208 - Registro de campo de 17/11/2009).
}

Na situação descrita, para Willian, o pertencimento de gênero que lhe foi significado na relação com as meninas o impossibilita de participar da dinâmica de troca de sandálias. Neste sentido, as crianças mostram como, em suas relações intergênero, as fronteiras são atualizadas, assumindo, tanto uma faceta potencializadora, quanto limitadora, de possibilidades de ação social das crianças. Por meio 
das relações estabelecidas com as meninas e das indicações dadas por elas, de que ele não poderia usar as sandálias, que são/estão definidas cultural e socialmente como femininas, a possibilidade de agir e participar do mundo social é limitada.

Uma segunda noção que deve acompanhar a análise de como as crianças trabalham culturalmente as fronteiras de gênero, é a de neutralização ${ }^{21}$ (THORNE, 1993), que consiste nos processos pelos quais, em suas relações geracionais (com outras crianças e com adultos), as crianças são capazes de neutralizar fronteiras de gênero fundadas na divisão e na oposição. $\mathrm{O}$ episódio da pesquisa de Buss-Simão (2012) que se segue, permite evidenciar como elas expressam esses processos:

As crianças Willian, Bianca, Amanda, Ana Laura e Nicole estão na casinha do parque e brincam
com um jogo do Batman como se fosse um jogo de memória; todavia, as peças ficam viradas
para cima e cada criança pode escolher as duas peças que desejam. Observo que Nicole está
usando as sandálias de Willian, e ele está descalço. Logo em seguida, Ana Laura convida Willian,
Amanda, Bianca e Nicole para irem até a sala do Grupo 4, onde se ouve música e as crianças
dançam e brincam. No caminho até lá, Willian pede suas sandálias, pois seus pés estão doendo
ao caminhar na areia. Nicole quer continuar usando as sandálias de Willian e então pede para
ficarem com os sapatos trocados. Voltam até a casinha e Nicole oferece suas sapatilhas para
Willian e, quando ela as coloca nos pés dele, diz:
Nicole: Ficou lindo, Willian. Ficou lindo, Willian... olha aqui [fala para mim].
Em seguida, caminham até onde estão Bianca e Ana Laura (BUSS-SIMÃO, 2012, p. 212 -
Registro de campo de $05 / 11 / 2009$ ).

O episódio, ao mostrar como o grupo de meninas abre brechas para a entrada de Willian na dinâmica da troca de sandálias - brincadeira presenciada de forma recorrente nas relações intragênero (entre as meninas) -, revela como o trabalho de fronteiras de gênero, entre as crianças, envolve processos de neutralização das relações fundadas na divisão e oposição. Revela também o caráter ambíguo e dúbio destas fronteiras. Se, por um lado, os limites podem ser acentuados, reforçados, ratificados, atualizados e reproduzidos nas relações intergênero, por outro, também podem ser desafiados, superados e questionados. Os processos de neutralização de relações de gênero, fundadas na divisão e oposição consistem, nesse sentido, no caráter transgressor e de resistência dos agenciamentos das crianças em seus modos próprios de trabalhar as fronteiras. Assim, pode-se dizer que a infância e, nela, as crianças, como sujeitos de um tempo que vê o novo naquilo que já é habitual e naturalizado no mundo social, permitem inaugurar diferentes formas de trabalhar o gênero. Esses episódios revelam o quanto a observação dos modos próprios como as crianças vivem sua infância nos dão pistas para compreender o modo como se dá a construção social da infância. Para além de uma forma social baseada na divisão sexual do trabalho (HIRATA e KERGOAT, 2007; KERGOAT, 2009) e em uma sociedade das imagens (FONTENELLE, 2006) heteronormativas e sexistas, as crianças experenciam as possibilidades de transitar e fruir pelos dois mundos, quando em relação, no coletivo pedagógico de pares.

Olhar para os sentidos que se produzem no interior das relações das crianças (inter e intragênero) nestes contextos, significa acentuar a produção de suas culturas, portanto, seus modos próprios de produzir sentido, de forma a compreender como lidam com as relações de gênero. $O$ trabalho pedagógico, ao dar sentido às resistências reveladas pelas crianças e aos seus processos de neutralização de relações de gênero baseadas em divisão e oposição potencializa, a partir disso, a construção de caminhos para um projeto educativo emancipador.

É inegável que o cuidado com as crianças pequenas é um trabalho que, em sua maioria, é realizado por mulheres, portanto, as relações geracionais, nomeadamente as relações de cuidado, das quais as crianças são dependentes das/os adultas/os são, em sua maioria, relações de gênero, porque são realizadas dentro de uma divisão sexual do trabalho (HIRATA, 1997; 2002; 2005; 2009; KERGOAT, 2009). Isto nos leva a refletir sobre as implicações políticas do cuidado pedagógico com crianças pequenas, entre as quais, a necessidade de considerar que as relações educativas na Educação Infantil (crianças-professoras/es), por se tratarem de relações sociais, são demarcadas por relações de gênero. Isto aponta para uma ação pedagógica que busque, em sua práxis, modos de trabalhar as fronteiras que questionem, desafiem e superem as relações baseadas em oposições e divisões de gênero. Algumas pistas

${ }^{21}$ No original: neutralization (THORNE, 1993).

Educação em Revista|Belo Horizonte|v.37|e25804|2021 
podem ser encontradas a partir da observação das interações e brincadeiras no coletivo de crianças e da identificação dos seus agenciamentos de resistências que, por sua vez, permitirão pensar sobre como potencializá-los em uma ação educativo-pedagógica.

Outra implicação política do cuidado pedagógico com crianças pequenas leva a questionar a categoria gênero, mas também a de geração, como categorias relativamente inequívocas e visíveis, sendo oportunamente utilizadas para separar mundos distintos que dividem, hierarquizam e classificam. Nos contextos de Educação Infantil, gênero e geração são categorias comumente utilizadas para demarcar fronteiras, sendo tomadas como princípio de classificação e de divisões "naturalizadas" e "socialmente aceitas" das suas formas organizacionais e de estruturação institucional. As crianças, de um modo geral, são agrupadas por faixa etária e, deste princípio até então apenas organizativo, passa-se a uma classificação de um conjunto de competências esperadas, muitas vezes, criando processos de exclusão.

Por sua vez, esses processos derivam de uma negação da heterogeneidade social da infância ao invisibilizar outros fatores que atravessam a experiência social das crianças que não apenas a idade, ou ainda, sua fase do desenvolvimento. Comumente, dentro desses grupos organizados por uma mesma faixa etária, as relações pedagógicas tendem a organizar as relações das crianças a partir de fronteiras opostas, binárias e divididas a partir do gênero. Ao analisar essas relações de gênero das crianças no contexto coletivo da Educação Infantil, a pesquisa de Buss-Simão (2012) permite compreender como as fronteiras criadas, nessas relações, não são fixas, mas 'trabalhadas' culturalmente, no caso das crianças pequenas, sobretudo, por meio das suas brincadeiras e relações com os pares.

Por fim, as pesquisas de Buss-Simão (2012) e Lessa (2019) ajudam a compreender as dimensões constitutivas das relações educativas na Educação Infantil, ao evidenciarem como as categorias gênero e geração são construídas nas dinâmicas que envolvem as relações das crianças com a dimensão do corpo e da alimentação.

\section{CONSIDERAÇÕES FINAIS}

O diálogo entre as duas pesquisas (BUSS-SIMÃO, 2012; LESSA, 2019) anuncia as categorias gênero e geração como dimensões do corpo e das práticas a ele vinculadas no contexto coletivo da Educação Infantil, portanto, dimensões constitutivas das relações de cuidado, levando em conta outros determinantes sociais, como classe e etnia/raça. Isto nos leva a considerar as implicações políticas das formas como o cuidado vem sendo concebido em nossa sociedade, uma vez que todo cuidado é educativo. Entretanto, por se tratar de relações, isso não quer dizer que todas convergem com um projeto político-pedagógico ou a um projeto educativo emancipatório. Barbosa e Quadros (2017, p. 47), ao atentarem para aquilo que são aprendizagens das práticas sociais e culturais presentes na vida cotidiana das crianças nas instituições de Educação Infantil, mostram como aquelas relacionadas aos cuidados pessoais ligadas ao corpo são ignoradas ou excluídas do debate pedagógico e curricular. De um modo geral, atribui-se às aprendizagens desses conhecimentos práticos uma origem familiar e anterior à experiência da Educação Infantil, o que leva a uma ação pedagógica voltada apenas em uma perspectiva do controle sob os corpos das crianças.

Juntas, as duas pesquisas mostram como essas categorias se produzem relacionalmente, indicando que o trabalho de fronteiras entre gêneros é produzido e ressignificado no interior dos processos de geracionalização em que a infância se constrói. Com base nesses pressupostos, tanto as gerações não se definem apenas pelas idades - infância juventude, por exemplo -, quanto o gênero são se define apenas pelo sexo, mas são fenômenos interdependentes das estruturas de relações em que se desenvolvem.

Com base em Tronto (2016), finalizamos esta discussão do cuidado, que não se esgota, pelo contrário, permanece aberta, lembrando que concebê-lo implica em um reconhecimento como elemento central da vida humana, "uma parte essencial do que significa ser humano. Não se pode entender a humanidade sem entender o que significa cuidar dos demais". Pressupõe reconhecer que o cuidado se estabelece de forma relacional e que "existem muitos tipos de relações diferentes, incluindo aquelas de opressão, que implicam o cuidado" (TRONTO, 2016, s/p.), sendo essas relações também de poder. Refletir sobre o cuidado exige atentar para o seu reconhecimento descolado de uma ideia romantizada que tende a restringi-lo como algo visto apenas como um "bom cuidado", pois tratar do cuidado não 
significa, necessariamente, um julgamento positivo. Qualificar o cuidado nos convoca a conceber aquilo que seria, então, um cuidado antissexista, anticlassista e antirracista e contra todas as formas de opressões etárias e capacitivas.

\section{REFERÊNCIAS}

ALANEN, Leena. Gender and Generation: Feminism and the "Child Question". In: QVORTRUP, Jens; BARDY, Marjatta; SGRITTA, Giovanni B.; WINTERSBERGER, Helmut (Eds.). Childhood Matters: Social Theory, Practice and Politics. Aldershot: Avebury, 1994. p. 27-42.

ALANEN, Leena. Explorations in generational analysis. In: ALANEN, Leena.; MAYALL, Berry. Conceptualizing child-adult relations. London: Routledge Falmer, 2001. p. 11-23.

ALANEN, Leena. Generational Order. In: QVORTRUP, Jens.; CORSARO, William A.; HONIG, Michael-Sebastian. (Eds.). The Palgrave handbook of childhood studies. England: Palgrave Macmillan, 2009. p. 159-175.

ALANEN, Leena. Moving towards a relational sociology of childhood. In: BRACHES-CHYREK, Rita; RÖHNER, Charlotte; SÜNKER, Heinz. (Eds.). Kindheiten Gesellschaften: Interdiziplinare Zugänge zur Kindheitsforschung. Opladen/Germany: Barbara Budrich Verläg, 2012. p. 21-44. [Manuscrito].

ALANEN, Leena. Repensando a infância, com Bourdieu. Revista NUPEM, Campo Mourão, v. 6, n. 11, pp. 39-55, jul./dez. 2014.

ALCOCK, Sophie. Playing with rules around routines: children making mealtimes meaningful and enjoyable. Early Years: An International Research Journal, Abingdon, v. 27, n. 3, p. 281-293, 2007.

ALMEIDA, Ana Nunes de; ALVES, Nuno de Almeida; DELICADO, Ana; CARVALHO, Tiago. Crianças e internet: a ordem geracional revisitada. Análise Social, Lisboa, v. 207, n. 48, p. 340-365, 2013.

BARBOSA, Maria Carmen S. Pedagogia da infância. In: GESTRADO/UFMG - Grupo de Estudos sobre Política Educacional e Trabalho Docente da Faculdade de Educação da Universidade Federal de Minas Gerais. DICIONÁRIO: trabalho, profissão e condição docente. Belo Horizonte: UFMG/Faculdade de Educação, 2010. [CDROM].

BARBOSA, Maria Carmen Silveira; QUADROS, Vanessa da Silva Rocha de. As aprendizagens cotidianas: os cuidados pessoais das crianças como gesto curricular. Em Aberto, Brasília, v. 30, n. 100, p. 45-70, set./dez. 2017.

BARTH, Fredik. Ethnic groups and boundaries. Londres: G. Allen and Unwin, 1969.

BEARDSWORTH, Alan; KEIL, Teresa. Sociology on the menu: an invitation to the study of food and society. London: Routledge, 1997.

BOURDIEU, Pierre. Razões práticas: sobre a teoria da ação. Campinas/SP: Papirus, 1996.

BOURDIEU, Pierre. Esboço de uma teoria da prática: precedido de três estudos de etnologia Cabila. Oeiras, PT: Celta, 2002.

BOURDIEU, Pierre. Sobre o Estado: Cursos no College de France (1989-92). 1a ed. São Paulo: Companhia das Letras, 2014. 
BUSS-SIMÃO, Márcia. Relações sociais em um contexto de educação infantil: um olhar sobre a dimensão corporal na perspectiva de crianças pequenas. Tese (Doutorado em Educação) - Programa de Pós-Graduação em Educação, Universidade Federal de Santa Catarina, Florianópolis/SC, 2012.

BUSS-SIMÃO, Márcia. Relações sociais de gênero na perspectiva de crianças pequenas na creche. Cadernos de Pesquisa, v. 43, n. 148, p. 176-197, Jan./Abr. $2013 a$.

BUSS-SIMÃO, Márcia. Gênero como possibilidade ou limite da ação social: um olhar sobre a perspectiva de crianças pequenas em um contexto de educação infantil. Revista Brasileira de Educação, Rio de Janeiro, v. 18, n. 55, p. 939-960, 2013b.

BRASIL. Câmara de Educação Básica, Conselho Nacional de Educação, Ministério da Educação. Resolução n. 05, de 17 de dezembro de 2009. Fixa as Diretrizes Curriculares Nacionais para a Educação Infantil. Diário Oficial da União, Brasília, DF, 18 dez. 2009.

BRASIL. Ministério da Educação. Fundo Nacional de Desenvolvimento da Educação. Resolução n. 26, de 17 de junho de 2013. Dispõe sobre o atendimento da alimentação escolar aos alunos da educação básica no âmbito do Programa Nacional de Alimentação Escolar - PNAE. Diário Oficial da União, Brasília, 18 jun. 2013.

CASTRO, Bárbara; CHAGURI, Mariana. Um tempo só para si: gênero, pandemia e uma política científica feminista. Blog DADOS, 2020 [publicado em 22 Mai. 2020]. Disponível em: $<$ http://dados.iesp.uerj.br/pandemia-cientifica-feminista/>.

CERISARA, Ana Beatriz. Professoras de educação infantil: entre o feminino e o profissional. São Paulo: Cortez Editora, 2002.

CERISARA, Ana Beatriz. Em busca do ponto de vista das crianças nas pesquisas educacionais: primeiras aproximações. In: SARMENTO, Manuel J.; CERISARA, Ana Beatriz (Orgs.). Crianças e Miúdos: perspectivas sociopedagógicas da infância e educação. Porto/Portugal: Edições ASA, 2004. p. 35-54.

COMORETTO, Géraldine. Le repas à la cantine: une expérience forcément négative? In: DUBET, F. Que manger? Paris: La Découverte, 2017. p. 151-163.

CHRISTENSEN, Pia H. Børn, mad og daglige rutiner. Barn, n. 2-3, p. 119-135, 2003.

CHRISTENSEN, Pia H.; JAMES, Allison. Investigação com crianças: perspectivas e práticas. Porto, Escola Superior de Educação Paula Frassinetti, 2005.

DORRER, Nika; MCINTOSH, Ian; PUNCH, Samantha; EMOND, Ruth. Children and food practices in residential care: ambivalence in the 'institutional' home. Children's Geographies, 8:3, p. 247-259, 2010.

EMOND, Ruth; MCINTOSH, Ian; PUNCH, Samantha. Food and feelings in Residential Childcare. British Journal of Social Work, 44, p. 1840-1856, 2014.

FARIA, Ana Lúcia Goulart de. A contribuição dos parques infantis de Mário de Andrade para a construção de uma pedagogia da educação infantil. Educação \& Sociedade (Impresso), v. 20, p. 6091, 1999.

FERREIRA, Maria Manuela M. “- A gente aqui o que gosta mais é de brincar com os outros meninos!" - As crianças como atores sociais e a (re) organização social do grupo de pares no cotidiano de um Jardim de Infância. Tese (Doutoramento em Ciências da Educação) - Programa 
Doutoral em Ciências da Educação, Faculdade de Psicologia e Ciências da Educação, Universidade do Porto, 2002a.

FERREIRA, Manuela. O trabalho de fronteira nas relações entre géneros em espaços de 'brincar ao fazde-conta'. Ex Aequo, 7, p. 113-128, 2002 b.

FONTENELLE, Isleide Arruda. Ilusões de modernidade: o fetiche da marca McDonald's no Brasil. Psicologia \& Sociedade, Belo Horizonte/MG, Associação Brasileira de Psicologia Social, v. 18, n. 2, p. 38-46, mai./ago. 2006.

GARNIER, Pascale; RAYNA, Sylvie. (Eds.). Recherche avez les jeunes enfants: perspectives internationales. Bruxelas: P.I.E Peter Lang, 2017.

GRAUE, M. Elizabeth; WALSH, Daniel J. Investigação etnográfica com crianças: teorias, métodos e ética. Lisboa: Fundação Calouste Gulbenkian, 2003.

HAICAULT, Monique. La gestion ordinaire de la vie en deux. Sociologie du Travail, Association pour le développement de la sociologie du travail, 26, Travail des femmes et famille (3), p. 268-277, 1984.

HIRATA, Helena. Division sexuelle du travail: état des connaissances. In: SOARES, Angelo (Org.). Stratégies de résistance et travail des femmes. 1ed. Montreal e Paris: L’Harmattan, 1997. p. 25-47.

HIRATA, Helena. Nova divisão sexual do trabalho? Um olhar voltado para a empresa e a sociedade. 1. ed. São Paulo: Boitempo, 2002.

HIRATA, Helena. Globalização, Trabalho e Gênero. Revista de Políticas Públicas, v. 9, n. 1, p. 111 128, jul./dez. 2005. ISSN 2178-2865 (online). Disponível em: <http://www.periodicoseletronicos.ufma.br/index.php/rppublica/article/view/3770>. Acesso em 19 Mai. 2020.

HIRATA, Helena. A precarização e a divisão internacional e sexual do trabalho. Sociologias (UFRGS. Impresso), Porto Alegre, ano 11, n. 21, p. 24-41, jan./jun. 2009.

HIRATA, Helena; LABORIE, Françoise; LE DOARÉ, Hélène; SENOTIER, Danièle (Orgs.). Dicionário crítico do feminismo. São Paulo: Fundação Editora da UNESP, 2009. Disponível em: <https://edisciplinas.usp.br/pluginfile.php/4098403/mod_resource/content/1/Kergoat\%20p.6775\%20in\%20Dicionario_critico_do_feminismo\%202009.pdf>. Acesso em 19 Mai. 2020.

HIRATA, Helena; KERGOAT, Danièle. "Novas configurações da divisão sexual do trabalho". Cad. Pesqui., São Paulo, v. 37, n. 132, p. 595-609, 2007.

JAMES, Allison; KJORHOLT, Anne Trine; TINGSTAD, Vebjorg (Eds.). Children, food and identity in everyday life. Basingstoke, UK: Palgrave Macmillan - Studies in Childhood and Youth, 2009.

KELLE, Helga. Mädchenkultur - Jungenkultur oder eine Kultur der Zweigeschlechtlichkeit? Feministische Studien. 15 Jahrgang. Nr. 2, p. 131-142, 1997.

KELLE, Helga. Geschleterterritorien: eine ethnographische Studie über Spiele neun-bis zwölfjäriger Schulkinder. Zeitschrift für Erziehungswissenschaft. 2 jahrg. p. 211-228, 1999.

KELLE, Helga. Gender and Territoriality in games played by nine-to-twelve-year-old Schoolchildren. Journal of Contemporary Ethnography. Vol. 29, n. 2, p. 164-197. 2000. 
KERGOAT, Danièle. Divisão sexual do trabalho e relações sociais de sexo. In: HIRATA, Helena; LABORIE, Françoise; LE DOARÉ, Hélène; SENOTIER, Danièle (Orgs.). Dicionário crítico do feminismo. São Paulo: Fundação Editora da UNESP, 2009. p. 67-75.

KUHLMANN JR., Moysés. Instituições pré-escolares assistencialistas no Brasil (1899-1922). Cadernos de Pesquisa, São Paulo, v. 78, p. 17-26, 1991.

LESSA, Juliana Schumacker. Infância, educação e processos geracionais: um estudo das relações e práticas do comer das crianças em um contexto público de educação infantil. Tese (Doutorado em Educação) - Programa de Pós-Graduação em Educação, Universidade Federal de Santa Catarina, Florianópolis/SC, 2019.

MATHIOT, Louis. L'alimentation des enfants: un observatoire des cultures enfantines et des rapports intergénérationnels. Thèse (Doctorat en Sociologie). École doctorale Sciences humaines et sociales, Université de Strasbourg, 2012.

QVORTRUP, Jens. (Ed.). Studies in modern childhood: society, agency, culture. United Kingdom: Palgrave Macmillan, 2005.

QVORTRUP, Jens; BARDY, Marjatta, SGRITTA, Giovanni, WINTERSBERGER, Helmut (Eds.). Childhood matters: social theory, practice and politics. Aldershot/UK: Avebury, 1994.

ROCHA, Eloisa Acires Candal. A pesquisa sobre educação infantil: trajetórias e perspectivas. Perspectiva, Florianópolis, v. 17, n. 1, p. 61-71, jan. 1999. ISSN 2175-795X. Disponível em: <https://periodicos.ufsc.br/index.php/perspectiva/article/view/10547>. Acesso em: 07 jun. 2020.

ROCHA, Eloisa Acires Candal; LESSA, Juliana S.; BUSS-SIMÃO, Márcia. Pedagogia da Infância: interlocuções disciplinares na pesquisa em Educação. Da Investigação às Práticas, 6 (1), Lisboa, p. 31 49, 2016. Disponível em: <https://repositorio.ipl.pt/bitstream/10400.21/6435/1/97-304-1-PB-1.pdf>. Acesso em 14 jun. 2020.

ROSEMBERG, Fúlvia. Organizações multilaterais, estado e políticas de educação infantil. Cadernos de Pesquisa, n. 115, p. 25-63. 2002. Disponível em: <http://www.scielo.br/pdf/cp/n115/a02n115.pdf>.

SARMENTO, Manuel Jacinto. O estudo de caso etnográfico em educação. In: ZAGO, Nadir; CARVALHO, Maria Pinto de; VILELA, Rita Amélia Teixeira. Itinerários de pesquisa: perspectivas qualitativas em sociologia da educação. Rio de Janeiro: DP\&A, 2003. p.137-179.

TURNER, Sheila; MAYALL, Berry; MAUTHNER, Melanie. One big rush: dinner- time at school. Health Education Journal, n. 54, p. 18-27, 1995.

THORNE, Barrie. Gender Play: girls and boys in school. Buckingham/UK: University Press Buckingham, 1993.

TRONTO, Joan. Entrevista: "Cuidar no es más natural para las mujeres, lo hacen por el privilegio de los hombres". El Diario-Espanha-Catalunya, Barcelona, ES, 30 de set. 2016. Disponível em: <https://www.eldiario.es/catalunya/barcelona/Cuidar-natural-mujeres-privilegio-

hombres_0_564493953.html>. Acesso em 15 jan. 2020.

VIANNA, Claudia Pereira. A feminização do magistério na educação básica e os desafios para a prática e a identidade coletiva docente. In: YANNOULAS, Silvia Cristina (Org.). Trabalhadoras: análise da feminização das profissões e ocupações. Brasília, DF: Abaré, 2013. p. 159-180. 
VIEIRA, Lívia Maria Fraga. Mal necessário: creches no departamento nacional da criança (1940-1970). Cadernos de Pesquisa, São Paulo, v. 67, 3-16. 1988.

WINTERSBERGER, Helmut. Work, Welfare and Generational Order: towards a political economy of childhood. In: QVORTRUP, Jens. (Ed.). Studies in modern childhood: society, agency, culture. United Kingdom: Palgrave Macmillan, 2005. p. 201-221.

Submetido: $13 / 10 / 2020$

Aprovado: 09/02/2021 